\title{
The Extent of Inclusion (TIMSS-2019) Standards of Mathematics Book Scheduled for the Fourth Grade Students in Jordan from Maths Teachers' Point of View for the Fourth Grade Students
}

\author{
Awad Mufleh Shihab Alkhazam ${ }^{1}$ \\ ${ }^{1}$ Faculty of Educational Sciences, Department of Curriculum and Instruction, The World Islamic Sciences \& \\ Education University, Amman- Jordan \\ Correspondence: Awad Mufleh Shihab Alkhazam, Faculty of Educational Sciences, Department of Curriculum \\ and Instruction, The World Islamic Sciences \& Education University, Amman- Jordan
}

Received: November 11, 2019

Accepted: November 25, 2019 Online Published: November 26, 2019

doi:10.5539/mas.v13n12p61

URL: https://doi.org/10.5539/mas.v13n12p61

\begin{abstract}
This study was conducted to find out the Extent of Inclusion (TIMSS-2019) Standards of mathematics book scheduled for the Fourth Grade Students in Jordan from Maths teachers' point of view for the Fourth Grade Students. The study sample consisted of 300 Maths teachers for the Fourth Grade Students in Mafraq governorate. This study used the descriptive methodology. To this study, the researcher has prepared a list of criteria (TIMSS-2019) to be included in the mathematics book scheduled for the Fourth Grade Students in Jordan, and then organized these standards in the form of a questionnaire consisting of two dimensions are (content and knowledge) emanates from each of them (3) domains and under them (43) sub-standards criteria from (School Mathematics Assessment frame work,TIMSS-2019). The researcher then turned this list into a questionnaire which describing the final degree of inclusion of the six areas, to find out the Extent of Inclusion Standards of mathematics book scheduled for the Fourth Grade Students in Jordan. The scale validity and reliability were verified.

The study results showed that the percentage of the Extent of Inclusion (TIMSS-2019) Standards of mathematics book scheduled for the Fourth Grade Students in Jordan from Maths teachers' point of view for the Fourth Grade Students was medium and a general percentage of $(66) \%$.
\end{abstract}

Keywords: (TIMSS-2019) Standards, mathematics book scheduled for the Fourth Grade Students, maths teachers for the Fourth Grade Students

\section{Introduction}

Countries are seeking to obtain an advanced ranking and status among countries, Countries use differing frequencies, classification systems and assessment methods, international comparisons of student achievement involve assessing the knowledge of elementary and secondary school students in subjects and then judging the classification and ranking of the state among the ranks of the countries which based on the evaluation of the achievement of these students, including these tests (TIMSS) global.

TIMSS (Trends in International Mathematics and Science Study) is a large-scale assessment designed to inform educational policy and practice by providing an international perspective on teaching and learning in mathematics and science, which it is a worldwide research project taking place every four years and providing data about trends in mathematics and science achievement over. In the USA at Boston College, this test is conducted under the supervision of the International Association for the Evaluation of Educational Achievement (International Association for The Evaluation of Educational Achievement )(IEA) Headquartered in Amsterdam / Netherlands, it is carried out every four years for the fourth and eighth grades of the participating countries. The first session was held in 1995 and consecutively until the seventh session in 2019. The Jordanian Ministry of Education is keen to keep pace with international trends in evaluating the educational process as possible. Jordan has participated in these tests since 1999 and until now (Mullis and others, 2008). 
the mathematics frameworks in ( TIMSS-2019) have been updated and are appropriate for both digital and paper assessment formats. The goal is to capitalize on the benefits of computer-based assessment to begin incorporating new and better assessment methods, especially in the applying and reasoning domains (Mullis and others, 2016 ).

Timss-2019 test focuses on two dimensions for the 4th class maths evaluation, and they are: the content and the knowledge, and every dimension has group of domain, content dimension Determine the material to be evaluated at certain percentages, while knowledge dimension determine thinking processes to be evaluated also at certain percentages, we find that the content include three domain, numbers $(50 \%)$, Measurement and Engineering $(30 \%)$, and data $(20 \%)$, While knowledge includes three main domains too: Knowledge (40\%), application (40\%), Reasoning/ inference (20\%), and every domain has main titles linked to it, and every title has Substandard criteria (School Mathematics Assessment frame work,TIMSS-2019)

If we take a closer look at Jordan's participation in this test from 1999 to 2015, the results were in the years in which Jordan participated $(1999,2003,2007,2011,2015)$, respectively $(428,424,427,406)$. In an analytical view of the previous results, it is noticeable that there was a significant decline in the last session in which it participated in (2015) compared to the previous results in which it participated. It is possible that the results achieved by the Jordanian students are a shock to the decision makers and those in charge of the educational system, which may be due to some individual educational policies, which have moved away from developing the essence of the educational process, and focused on the evaluation cycle in secondary education, deliberately forgetting the elements of the system. In terms of qualifying and training teachers and teaching methods, or empowering learners and developing curricula and textbooks, assessment stations at various stages, developing the educational environment and school administrations, developing the performance of educational supervisors, or focusing on the Jordan ranks 40th in the TIMSS Numeracy test, in which Jordan participated for the first time. 44 countries took part in this test. Singapore ranked first with a total score. (618), a difference higher than Jordan (230) points (Abu Libdeh, 2015).

There are several studies that have examined TIMSS tests and related standards and their availability in mathematics and science textbooks for the fourth and eighth grades in some countries. The results of the Tabaza(2018) study The overall percentage of the content domain in the light of the( TIMSS- 2015), standards for (4) grades, which it was as follows: numbers (80.24), geometric shapes and measurements (14.81), data display (4.75), the proportion of the cognitive dimension was as follows: knowledge (68.39), application (18.75), inference (12.85). The results of the Abu Kameel (2019) study showed that the overall percentage of the availability of TIMSS-2015 standards in the content of the Palestinian science curriculum for the eighth grade (30.5) is a small percentage.

Also the study of Lessani \& others (2014) conducted in Singapore also indicated that Singapore has a strong and sophisticated mathematics curriculum for the eighth grade, which led to the rise of students' scores in the TIMSS test during the years (1999-2011).

The results of Al-Hussan (2015) study concluded with a list of TIMSS requirements, which should be included in elementary science textbooks. Additionally, results revealed that the inclusion percentages of scientific inquiry were high in all grades, whereas the inclusion percentages of science content and cognitive domains were insufficient in science textbooks.

The results of Al-Grabli \& Al-Abed (2015) study indicated that there is a positive effect of a training program for math teachers based on the International Study Trends in Mathematics and Science (TIMSS), on the ability of their students in mathematical knowledge, application and reasoning. And Dudeen \& et al. (2012) study showed a positive relationship between the qualifications of mathematics teachers on the one hand and the achievement of students in the international test (TIMSS) on the other in Saudi Arabia and Taiwan. The results of Almasa'afah (2005) study showed that there is a variation in the availability of basic concepts in mathematics textbooks from the fourth to eighth grade in Jordan, where the ratio of numbers and operations $(49.7) \%$ is the most represented in the mathematics books of other concepts.

Teleni (2013) study showed that the content of the mathematics textbook for the fourth grade in Palestine is not compatible with the content and mental processes with the TIMSS test.

From the previous studies, there is a variation in the degree of mathematics textbooks for the fourth grade to the TIMSS test criteria. The mathematics textbook for the fourth grade in Jordan was developed after 2005 more than once. So this study was conducted to find out the Extent of Inclusion (TIMSS-2019) Standards of mathematics book scheduled for the Fourth Grade Students in Jordan from Maths teachers' point of view for the Fourth Grade Students. 


\section{Study Problem and Questions}

Most countries of the world seek to keep pace with global trends in evaluating the educational process through international assessments, where countries the world over publicly finance and manage the great majority of their schools, the institutions and policies established by various levels of government must create incentives for school personnel to use their resources in ways that maximize performance. Which (TIMSS) is a series of international assessments of the mathematics and science knowledge of students around the world. Due to Jordan's decline in ranking in the international rankings in the TIMSS test (2015) and its ranking (41) among other Arab countries compared to previous years, which draws to take into account for several reasons, which may include the verification of the book and the availability of TIMSS standards. Therefore, the study identified the problem of answering the main study question as follows: what is the Extent of Inclusion (TIMSS-2019) Standards of mathematics book scheduled for the Fourth Grade Students in Jordan from Maths teachers' point of view for the Fourth Grade Students?

Therefore, this study tried to answer the following two sub-questions:

1- What are the (TIMSS-2019) criteria to be included in the content of the mathematics book scheduled for the fourth grade in Jordan?

2- What is the percentage of the inclusion (TIMSS-2019) standards of mathematics book scheduled for the Fourth Grade Students in Jordan from Maths teachers' point of view for the Fourth Grade Students?

\section{Objectives of the Study}

This study was conducted to find out the Extent of Inclusion (TIMSS-2019) Standards of mathematics book scheduled for the Fourth Grade Students in Jordan from Maths teachers' point of view for the Fourth Grade Students.

This study seeks to:

1. Determine the list of (TIMSS-2019) Standards of mathematics book scheduled for the Fourth Grade Students in Jordan

2. Identify the degree of Inclusion (TIMSS-2019) Standards of mathematics book scheduled for the Fourth Grade Students in Jordan from Maths teachers' point of view for the Fourth Grade Students.

\section{The Importance of Study}

The importance of this study stems from the following:

1. TIMSS-2019 deals with the subject of Inclusion (TIMSS-2019) Standards of mathematics book scheduled for the fourth grade in Jordan, which it is very important for the teacher and learner in the processes of teaching, learning and educational evaluation.

2. This study sheds light on a new model related to the preparation, planning, design and development of mathematics book for the fourth grade in Jordan according to the (TIMSS-2019) standards.

\section{Terms of Study}

Mathematics Book for the Fourth Grade: is a mathematics course that is taught to students of the fourth grade in Jordan in the two semesters of the academic year 2018/2019 and consists of two parts distributed over two semesters.

(TIMSS-2019) Standards: Trends in International Mathematics And Science Studies which it is Global Trends in Mathematics and Science, it is a global tests to assess the achievement of students in mathematics and science, which is applied to students in the fourth and eighth grades and periodically at a rate of every four years. The researcher defines (TIMSS-2019) standards as a set of standard identified and formulated by the International Association for the Assessment of Educational Achievement in Mathematics for the fourth grade (IEA)

Maths Teachers for the Fourth Grade Students: All male and female math teachers who study math for fourth grade in government schools in Mafraq for the first semester of the academic year 2018/2019.

\section{The Limits of the Study}

Objective Limits: This study was limited to (TIMSS-2019) standards of mathematics book scheduled for the Fourth Grade Students for the first and second semesters of the academic year 2018/2019.

Humanity Limits: The application of the study was limited to Mathematics teachers (male and female) who teach mathematics for the fourth grade in public schools in Mafraq. 
Time Limits: The study was applied in the second semester of the academic year 2018/2019.

Spatial Limits: The study was implemented in the public schools where students and teachers of mathematics are available for the fourth grade in Mafraq- Jordan.

\section{Methods and Procedures}

\subsection{Research Method}

This study is based on the descriptive approach to find out the Extent of Inclusion (TIMSS-2019) standards of mathematics book scheduled for the Fourth Grade Students in Jordan from Maths teachers' point of view for the Fourth Grade Students.

\subsection{Study Society}

The study community is consisted of All the teachers of mathematics for the fourth grade who teach mathematics in public schools in Mafraq- Jordan during the second semester of the academic year 2018/2019, which consisted of (600) teachers, including (280) male teachers and (320) female teachers distributed on (540) public school.

\subsection{The Study Sample}

The sample was selected randomly by (50)\% of the study population, the study sample consisted of (300) teachers, (140) male and (160) female of mathematics teachers for the fourth grade in the schools of Mafraq Governorate.

Study Variables: This study consists of two variables:

- Independent variable: the teachers variables of mathematics for the fourth grade.

- Dependent variable: Percentage of inclusion (TIMSS-2019) standards in mathematics book for fourth grade.

\subsection{Study Instruments}

To achieve the objectives of this study and through the researcher on the theoretical framework of the International Study for the Assessment of School Mathematics (TIMSS-2019) issued by the International Association for the Evaluation of Educational Achievement, and through the researcher on the theoretical literature, studies, research and previous literature related to this study as a study of (Tabaza, 2018) and (abu kameel, 2019). The researcher has prepared a list of TIMSS-2019 standards that should be included in the mathematics book for the fourth grade and ensure its sincerity and suitability for students.

a questionnaire was developed to obtain the responses of the study sample members which consisted of (50) paragraph in its initial form, each one describing the six areas of study, which consisted of two dimensions, so that each includes three domains.

\subsection{Instrument Reliability}

It has been relied on content validity (validity of the experts) in order to ascertain the validity of the questionnaire by presenting it in its preliminary form to a committee consisted of (8) exports from the field of curricula and teaching methods, psychology and society of faculty members in universities and educational supervisors of mathematics and educational experts who trained on (TIMSS-2019) standards, in order to ascertain the validity of questionnaire items, the accuracy of resolution wording items, the accuracy and clarity of the item, the relevance of each item to its domain, its suitability to achieve the objective for which it was prepared, and to delete, add or modify any suggestions sound appropriate. So the seven paragraphs of the measure were deleted and (4) of them were modified based on the opinions of the arbitrators based on the consensus of the majority of the experts on the amendment procedure and the finalization of the questionnaire by $(93) \%$ on the occasion of the paragraphs of the scale (TIMSS-2019) and became the final number of paragraphs of the scale after Deletion and amendment (43) paragraph distributed into (6) domains and (2) dimensions.

\subsection{Instruments Validity}

In order to ensure the stability of the study tool, the tool was applied to the study sample which consisted of (35) mathematics teacher for the fourth grade from outside the study sample (from the study population), and then applied the scale for the second time, after a week from the first time on the same sample, and the stability of the measure was calculated by calculating the coefficient of stability, and the value of the total stability coefficient of the scale It is (92.0), which is acceptable for this study.

\subsection{Procedures for the Study Implementation}

After the study population was determined by the researcher to prepare a list of (TIMSS-2019) standards. The researcher transformed this list and organized it in a quadrant-related questionnaire (high degree, medium degree, low degree, not included). Study on the paragraphs of the tool and distributed to the sample of the study himself, 
and then Alba Urge a trustee to collect the tool in preparation for statistical processing. On the order of grades ( 3 , $2,1,0)$, the researcher defined the study sample on the paragraphs of the tool and distributed it to the study sample, then the researcher personally collected the tool in preparation for statistical processing.

\subsection{Statistical Processing}

To answer the study questions, the following statistical treatments were used statistical package for the social sciences (SPSS). Also the study used frequency and percentages arithmetic averages (means), standard deviation of the personal variables of the study sample were calculated.

\subsection{Scale Correction}

In order to determine the degree of inclusion (TIMSS-2019) Standards of mathematics book scheduled for the Fourth Grade Students. The researcher adopted quadrilateral gradient of alternatives (high degree, medium degree, low degree, not included). which corresponds in numbers, respectively $(3,2,1,0)$ to judge the extent to which the standards are included.

The researcher also adopted the following standards for judging the levels of the percentages of the study tool and its paragraphs, as shown in Table 2:

Table 2. Levels of percentages of inclusion in the study tool domains and paragraphs

\begin{tabular}{|c|c|c|}
\hline The inclusion ratio & Ratio at the level of paragraph & $\begin{array}{l}\text { Percentage on the field level or the } \\
\text { scale as a whole } \%\end{array}$ \\
\hline Low level & From 0 to 1 & $0-33$ \\
\hline Intermediate level & more than 1 to 2 & $34-$ \\
\hline High level & more than 2 to 3 & $68-$ \\
\hline
\end{tabular}

\section{Results of the Study and Discussion}

This section includes the results of the study aimed at identifying " to find out the Extent of Inclusion (TIMSS-2019) Standards of mathematics book scheduled for the Fourth Grade Students in Jordan from Maths teachers' point of view for the Fourth Grade Students " The First question is: " What are the (TIMSS-2019) Standards to be included in the mathematics book for the fourth grade in Jordan?

To answer the first question, the researcher reviewed the literature, studies and research related to the current research and the theoretical framework related to the TIMSS standards over the previous years, and the theoretical framework of the International Study of Mathematics and Science (TIMSS-2019) issued by the International Association for the Evaluation of Educational Achievement (IEA)) A list of Standards, which fall within two dimensions and (6) domains, has been identified after being presented to a group of arbitrators. The final list includes two dimensions: Content dimension and includes (3) areas: (preparation, measurement and engineering, data) and knowledge includes (knowledge, application, reasoning / collaboration) and falls under these areas (43) of (TIMSS-2019) standards and Table 3 shows the list of (TIMSS-2019) standards to be included in the math book scheduled for fourth grade basic in Jordan. 
Table 3. A list of the (TIMSS-2019) standards to be included in the fourth grade mathematics book in Jordan

\begin{tabular}{cc}
\hline Dimensions $\quad$ Domains & Standards \\
\hline $\begin{array}{c}\text { Knowledge of the spatial value of a number is shown in the two-digit } \\
\text { number up to six digits. }\end{array}$ \\
Represents the whole number using words, shapes, symbols and on the \\
line.
\end{tabular}

Adds and subtracts up to four-digit numbers with calculations to solve life problems.

Multiply numbers (even three-digit numbers) in a one-digit number and a two-digit number in a two-digit number that includes calculations to solve life problems.

Divide numbers up to three-digit numbers by a one-digit number containing calculations to solve life problems.

Solve problems involving odd and even numbers and multiples and numbers factors.

Round the numbers to the nearest ten thousand and find estimates.

Connect two properties of numbers or processes to solve verbal problems.

Find the missing number or the missing operation in the numeric sentence, example $(15+\mathrm{w}=22)$.

Identifies or writes numerical expressions or sentences to represent a mathematical problem that can include unknowns.

Numbers

Content

Defines and uses relationships in a known pattern (for example, describing the relationship between consecutive terms and writing pairs of whole numbers based on a given rule.

Recognizes fractions and parts of the whole or of groups.

Represent fractions using words, numbers, or forms.

Comparison of simple equivalent fractions.

Adds and subtracts simple fractions with denominators $(2+3+4+5+6$

$+8+10+12$ or 100) including solving life problems.

Demonstrate knowledge of the spatial value of decimal numbers, including their representation using words, numbers, or forms.

Adds and subtracts decimals from one or two places, including solving special life problems related to money.

Compares, ranks and rounds decimal numbers.

Measures lengths with rulers, estimates lengths (millimetres, centimetres, meters, kilometres) and solves problems involving lengths.

Solve problems involving mass (grams, kilograms), volume (millilitres),

Measurement and Engineering time (minutes, hours), identification of appropriate types and measurements of units, and reading of scales.

Solve problems including polygon circumference, area of rectangles, area of shapes covered by squares or parts of squares, and size of shapes filled with cubes.

Identifies and plots parallel and orthogonal lines, identifies and plots existing angles and angles smaller and larger than the list and compares 
angles (given without measurement).

Uses basic properties including linear and rotational symmetry to describe, compare and create familiar two-dimensional shapes (circle, triangle, quadrilateral, and other polygons).

Uses simple properties to describe and compare familiar three-dimensional shapes (cubes, prism, parallelogram, cone, cylinder and ball).

Reads and interprets data from the table, graphic representation with graphs, bar graphs, line graphs, and pie graphs.

Data

Knowledge

knowledge

Data is used to answer questions that do not rely solely on simply reading the data presented (e.g. solving problems, performing calculations using data from two or more sources and drawing conclusions based on the data).

Call definitions, terms, setup properties, units of measurement, geometric properties, as well as symbols (e.g. $a x b=a b, a+a+a=3 a)$.

Identify numbers such as expressions, quantities and shapes as well as identify mathematically equivalent objects such as equivalent fractions, decimal numbers and percentages: different directions for different geometric shapes.

Classification of numbers, expressions, quantities and shapes by general properties.

Performing arithmetic procedures Addition, subtraction, multiplication and division or in combination with total numbers, fractions, decimal numbers, integers, performs direct algebraic procedures.

Retrieves information from graphical representations, tables, texts or other sources.

Uses measurement tools: selects the appropriate units of measurement.

Identify appropriate processes, strategy, and tools to resolve issues that use familiar methods to resolve them.

Application

Display data in tables or graphs: Create equations, variations, geometric shapes or graphs / represent problem states, generate equivalent representations of given mathematical relationships or units.

Implement problem-solving strategies and processes that include familiar mathematical concepts and procedures.

Defines, describes, or uses relationships between numbers, expressions, quantities, and shapes.

Connects different elements of knowledge, related representations and procedures to resolve issues.

Reasoning / inference

Evaluate alternative strategies and methods for solving issues.

Reaches conclusions based on information and evidence.

Develop terms that represent relationships more generally and in terms that are widely applied.

Provides mathematical arguments to support strategy or solution.

Table 3 indicates that the number of TIMSS-2019 standards to be included in the mathematics book for the fourth basic grade (43) which fall within two dimensions are: dimension of content and after knowledge, as we can see from the data of the previous table also that the content dimension includes; Three main domains: preparation and fall under (19) standards, measurement and engineering and fall under (6) standards, and data and fall under (3) standards, while the dimension of knowledge also includes three other key domains, namely: 
knowledge and fall under (6) standards, The application falls under (3) standards, the inference (analysis) and falls under (6) standards.

Results related to the second question: What is the percentage of the inclusion (TIMSS-2019) standards of mathematics book scheduled for the Fourth Grade Students in Jordan from Maths teachers' point of view for the Fourth Grade Students?

To answer this question, the means and standard deviations were computed, table (4) shows means and standard deviations for all domains of study according to the study variables.

Table 4. Means, standard deviations and the general percentage of inclusion for the study tool domains

\begin{tabular}{|c|c|c|c|c|c|}
\hline $\begin{array}{l}\text { The } \\
\text { dimension }\end{array}$ & The Domains & $\begin{array}{c}\text { Number of } \\
\text { standards }\end{array}$ & Means & $\begin{array}{c}\text { Standard } \\
\text { deviations }\end{array}$ & $\begin{array}{l}\text { The percentage } \\
\text { of the overall } \\
\text { included } \%\end{array}$ \\
\hline \multirow{3}{*}{ Content } & Numbers & 19 & 2.5 & .65 & 83 \\
\hline & $\begin{array}{l}\text { Measurement and } \\
\text { Engineering }\end{array}$ & 6 & 2.4 & .81 & 79 \\
\hline & Data & 3 & 1.9 & .55 & 63 \\
\hline \multicolumn{2}{|c|}{ Domains the content as a whole } & 28 & 2.41 & .72 & 80 \\
\hline \multirow{3}{*}{ Knowledge } & Knowledge & 6 & 1.5 & .83 & 50 \\
\hline & Application & 3 & 1.2 & .76 & 40 \\
\hline & $\begin{array}{l}\text { Reasoning } \\
\text { inference }\end{array}$ & 6 & 1 & .92 & 33 \\
\hline \multicolumn{2}{|c|}{ Fields of knowledge as a whole } & 15 & 1.24 & .81 & 41 \\
\hline \multicolumn{2}{|c|}{$\begin{array}{l}\text { All areas of the two dimensions as } \\
\text { a whole }\end{array}$} & 43 & 2 & .77 & 66 \\
\hline
\end{tabular}

Table 4 shows that the overall percentage of (TIMSS-2019) Standards of mathematics book scheduled for the Fourth Grade Students in Jordan from Maths teachers' point of view for the Fourth Grade Students is (66)\%, which is an average, where the domains of the content dimension combined as a whole a percentage of $(80) \%$ which it is high, The domains of numbers in this dimension has the highest percentage of $83 \%$ which it is high. As for the data domain, it received the lowest percentage of (63)\%. While the domain of knowledge as a whole obtained a percentage of $(41) \%$, Where the domain of knowledge got the highest percentage of $(50) \%$, while the domain of inference / reasoning has obtained the lowest percentage of (33)\%, which it is low.

Table 5 shows means and standard deviations for all domains of study according to the study variables. 
Table 5. Means, standard deviations and the general percentage of the responses of the study sample to each paragraph of the study tool

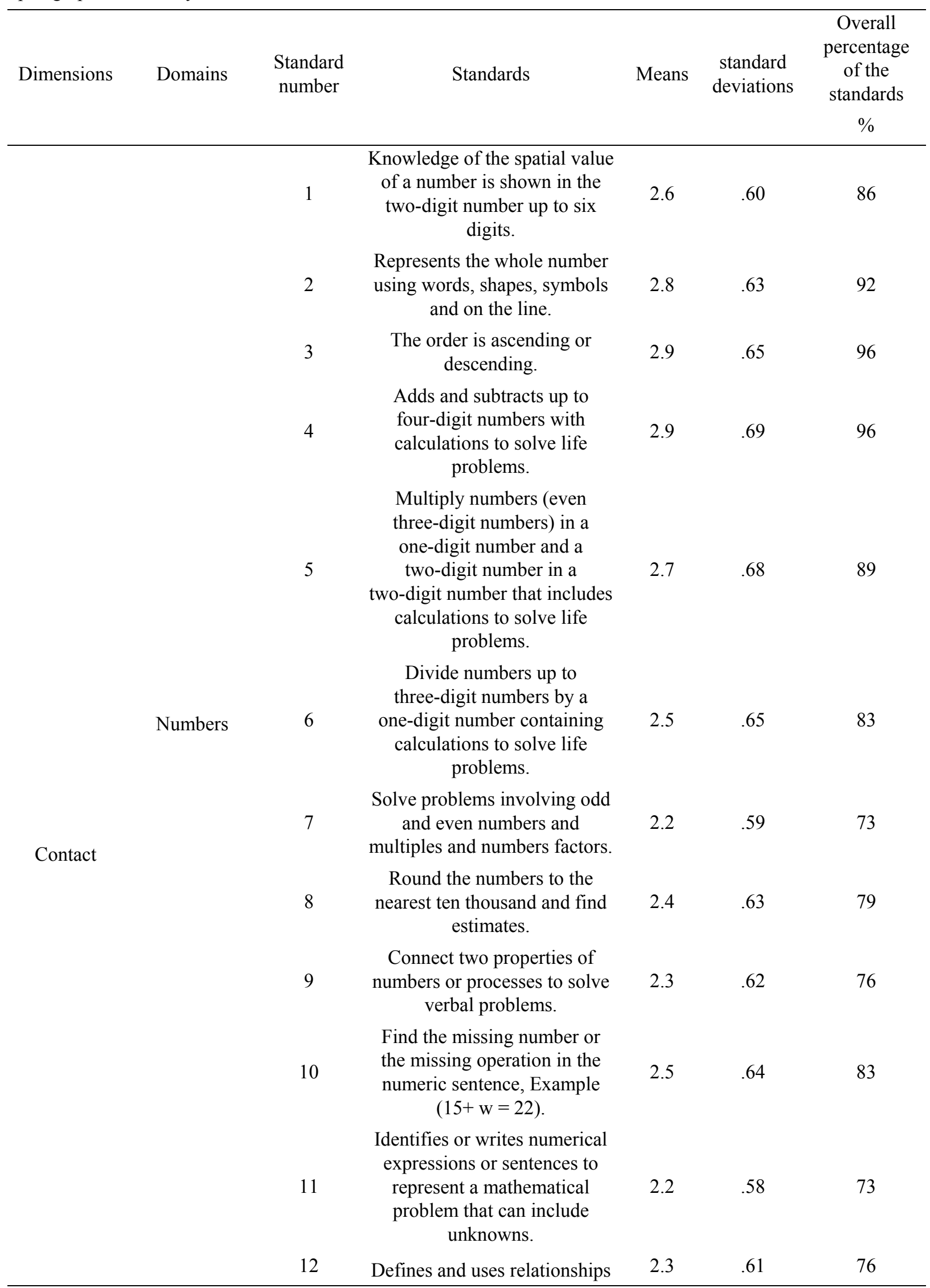


in a known pattern (for

example, describing the

relationship between

consecutive terms and writing

pairs of whole numbers based on a given rule).

Recognizes fractions and parts of the whole or of groups.

$2.8 \quad .66$

Represent fractions using words, numbers, or forms.

$2.7 \quad .55$

Comparison of simple equivalent fractions.

Adds and subtracts simple fractions with denominators (2

$+3+4+5+6+8+10+12$

or 100) including solving life problems.

Demonstrate knowledge of the spatial value of decimal representation using words, numbers, or forms.

Adds and subtracts decimals from one or two places, including solving special life problems related to money.

Compares, ranks and rounds decimal numbers.

Measures lengths with rulers, estimates lengths (millimetres,

Solve problems involving mass (grams, kilograms), volume (millilitres, litters), time (minutes hours), identification of appropriate

Measurement and Engineering types and measurements of units and reading of scales.

Solve problems including polygon circumference, area of rectangles, area of shapes covered by squares or parts of squares, and size of shapes filled with cubes.

Identifies and plots parallel and orthogonal lines, identifies and plots existing angles and angles smaller and larger than the list and compares angles (given without measurement).

$\begin{array}{lll}2.9 & .76 \quad 96\end{array}$

$\begin{array}{lll}2.4 & .83 & 79\end{array}$

$2.5 \quad .85$

83 


\begin{tabular}{|c|c|c|c|c|c|c|}
\hline & & 5 & $\begin{array}{l}\text { Uses basic properties } \\
\text { including linear and rotational } \\
\text { symmetry to describe, } \\
\text { compare and create familiar } \\
\text { two-dimensional shapes } \\
\text { (circle, triangle, quadrilateral, } \\
\text { and other polygons). }\end{array}$ & 1.9 & .79 & 63 \\
\hline & & 6 & $\begin{array}{l}\text { Uses simple properties to } \\
\text { describe and compare familiar } \\
\text { three-dimensional shapes } \\
\text { (cubes, prism, parallelogram, } \\
\text { cone, cylinder and ball). }\end{array}$ & 2.1 & .78 & 69 \\
\hline & & 1 & $\begin{array}{l}\text { Reads and interprets data from } \\
\text { the table, graphic } \\
\text { representation with graphs, bar } \\
\text { graphs, line graphs, and pie } \\
\text { graphs. }\end{array}$ & 2.3 & .52 & 76 \\
\hline & & 2 & $\begin{array}{l}\text { Organize and present data to } \\
\text { help answer the questions } \\
\text { given. }\end{array}$ & 1.8 & .57 & 60 \\
\hline & Data & 3 & $\begin{array}{l}\text { Data is used to answer } \\
\text { questions that do not rely } \\
\text { solely on simply reading the } \\
\text { data presented (example, } \\
\text { solving problems, performing } \\
\text { calculations using data from } \\
\text { two or more sources and } \\
\text { drawing conclusions based on } \\
\text { the data). }\end{array}$ & 1.6 & .55 & 53 \\
\hline & & 1 & $\begin{array}{l}\text { Call definitions, terminology, } \\
\text { setup properties, units of } \\
\text { measurement, geometric } \\
\text { properties, as well as symbols } \\
\text { such as }(\mathrm{a} \times \mathrm{b}=\mathrm{ab}, \mathrm{a}+\mathrm{a}+\mathrm{a}= \\
\text { 3a). }\end{array}$ & 1.3 & .82 & 43 \\
\hline Knowledge & Knowledge & 2 & $\begin{array}{l}\text { Identify numbers such as } \\
\text { expressions, quantities and } \\
\text { shapes as well as identify } \\
\text { mathematically equivalent } \\
\text { objects such as equivalent } \\
\text { fractions, decimal numbers } \\
\text { and percentages: different } \\
\text { directions for different } \\
\text { geometric shapes. }\end{array}$ & 1.8 & .85 & 59 \\
\hline & & 3 & $\begin{array}{l}\text { Classification of numbers, } \\
\text { expressions, quantities and } \\
\text { shapes by general properties. }\end{array}$ & 1.4 & .81 & 46 \\
\hline & & 4 & $\begin{array}{c}\text { Performing arithmetic } \\
\text { procedures Addition, } \\
\text { subtraction, multiplication and } \\
\text { division or in combination } \\
\text { with total numbers, fractions, }\end{array}$ & 1.9 & .84 & 63 \\
\hline
\end{tabular}


decimal numbers, integers, performs direct algebraic procedures.

5

Retrieves information from graphical representations, tables, texts or other sources.

$1.1 \quad .88$

Uses measurement tools:

6 selects the appropriate units of measurement.

Identify appropriate processes, strategy, and tools to resolve issues that use familiar methods to resolve them.

Display data in tables or graphs: Create equations, variations, geometric shapes or

Application

2 graphs / represent problem states, generate equivalent representations of given mathematical relationships or units.

Implement problem-solving strategies and processes that include familiar mathematical concepts and procedures.

Defines, describes, or uses relationships between numbers, expressions, quantities, and shapes.

1.5

$1.4 \quad .78$

46

Connects different elements of knowledge, related

Reasoning /

2

inference

representations and procedures to resolve issues.

Evaluate alternative strategies and methods for solving issues.

Reaches conclusions based on information and evidence.

$1.5 \quad .87$

Develop terms that represent relationships more generally and in terms that are widely applied.

Provides mathematical arguments to support strategy or solution.
0.8

$$
.90
$$

$\begin{array}{lll}1.1 & .95 & 36\end{array}$

0.9

2 .77 66

The tool as a whole for two dimensions

Table 4 indicate that the percentage of the inclusion TIMSS-2019 in the fourth grade mathematics course ranges from (23 to 96) and that the general percentage of the inclusion of the mathematics book for the fourth grade of the TIMSS-2019 standards was (66\%), in content dimension we note that each of the third and fourth standards in the domain of preparation, which provides for "arranging the numbers in ascending or descending order," adding and subtracting up to four-digit numbers containing calculations to solve life problems. The highest percentage (96). Whereas, standard no. (17) which provides for "showing knowledge of the spatial value of 
decimal numbers including their representation using words, numbers or models" obtained the lowest percentage in this area and the amount (63), but in the domain of measurement and engineering, we find that The first standard, which provides for "measuring lengths by ruler and estimating lengths (millimetres, centimetres, meters, kilometres) and solving problems involving lengths" has obtained the highest percentage (96), which is high, while the standard (5) in this area "Uses basic properties including linear and rotational symmetry Describe, compare and create familiar two-dimensional shapes (circle, triangle, quadrilateral, and other polygons) "at the lowest percentage (63). Finally, in the field of data from this dimension we find that the standard (1), which provides for "read and interpret data from the table and the graphical representation of the graphs and graphs and the graphical representation of lines and circular graphical representation" got the highest percentage and the amount of (78), which is high, while standard 3, which states that "data is used to answer questions that do not depend solely on the mere reading of the data presented (eg solving problems, calculating data from two or more sources and drawing conclusions based on the data), has obtained the lowest A percentage of (53) is Ratio of medium.

The researcher attributes the different ratios between the three content areas to the different mathematical nature of the three content areas. Concepts related to preparation and operations on students. Therefore, the researcher believes that the relevant international standards are included in the book more than others, and the proportion of the domain of preparation standards in the test (TIMSS-2019) in the content of the textbook of mathematics for the fourth grade is greater than other ratios related to other domains, while other areas such as engineering and measurement. The data are less degree for students and include in the book for the nature of the students age, where the focus is on the numbers more than others in this dimension, followed by the domain of engineering and then the domain of data.

In the dimension of knowledge, we note from the previous table that the standard No. (4) in the domain of knowledge, which provides "to perform arithmetic procedures addition, subtraction, multiplication and division or in combination with the total numbers, fractions, decimal numbers, integers, performs direct algebraic procedures" has occurred The highest percentage (63), which is an average, while the standard (5) in the same domain, which it is "retrieve information from graphical representations, tables, texts or other sources" obtained the lowest percentage of (36), In the domain of application, the standard (2) which provides for "displaying data in tables or graphs: creating equations, variations, geometric shapes or graphs / representing cases of problem, generating equitable representations of given mathematical relationships or units" The highest percentage (46), which is an average, while the standard (1) of this area, which provides for "the identification of appropriate processes, strategy, and tools to solve problems that use methods that are familiar to solve" got the lowest percentage of (33), Finally, in the domain of reasoning, standard (1), which provides for "defines, describes, or uses the relationships between numbers, expressions, quantities, and figures" obtained the highest percentage (50), which is an average, while the standard (6) "providing mathematical arguments or evidence to support strategy or solution" at the lowest percentage is (23) which is low, the results of this study agreed with (Tabaza, 2018)study.

The researcher attributes this to the fact that the nature of the students age does not require a large focus on some domains of knowledge, especially with regard to the application and reasoning because it is new concepts for students compared to the domain of the previous content.

\section{Recommendations}

In the light of the results concluded to, the researchers recommends the following:

-The need to introduce the fourth grade mathematics teachers to the TIMSS-2019 standards and their importance, emphasizing it and establishing their concepts among students.

-Holding training courses for mathematics teachers o for the fourth grade on (TIMSS-2019) standards and mechanisms for the development of students.

- The need to train fourth grade mathematics teachers to formulate test questions for students cantered on (TIMSS-2019) standard.

-Redevelopment of the mathematics book for the fourth grade and include the content of (TIMSS-2019) standards more than it, especially in the dimension of knowledge related to the domain of application and reasoning. 


\section{References}

Al-Hussan, \& Amani. (2015). The extent of the achievement of the International Trends in Mathematics and Science Study (TIMSS-2015) in the first to fourth grade science textbooks in Saudi Arabia. Zarqa Journal for Research and Human Studies, 15(1), 111-132. Zarqa University: Jordan.

Al-Gharabli, Mustafa, Al-Abed, \& Adnan. (2015). The impact of training program for mathematics teachers based on the international study trends in mathematics and science (TIMSS) on the ability of their students on mathematical knowledge, application and mathematical inference. Dirasat Journal, Faculty of Educational Sciences - University of Jordan, 42(3), 1116--1135. Amman: Jordan.

Abu Kameel, \& Ruba Al-Sayed Mohammed. (2019). The extent to which the content of the Palestinian science textbook for the eighth grade of (TIMSS-2015) standards. the Journal of the Islamic University of Educational and Psychological Studies, 27(3), 791-817. Islamic University of Gaza.

Abu Libdeh, \& Hattab et al. (2015). National Center for Human Resources Development. Jordan National Report on the International Study of Mathematics and Science 2015 (TIMSS 2015), Amman: Jordan.

Al-masa'afah, \& Jameel. (2005). A grade representing mathematics textbooks for grades four through eight in Jordan for the main concepts and form and levels of questions in the TIMSS-R test, an unpublished master thesis University of Jordan: Amman: Jordan.

Dudeen,H., Abdelfattah, F., Shmrani,S. \& Hilal,M. (2012). The effects of teachers qualifications, practices and perceptions on student achievment in TIMSS mathematics acomparison of two countries. International Journal of testing, 12(1), 61-71. https://doi.org/10.1080/15305058.2011.621568

Tabaza, \& Walaa Hamza. (2018). Evaluation of the content of the Palestinian mathematics curriculum for the fourth and eighth grade in the light of TIMSS standards, unpublished Master Thesis, Islamic University of Gaza.

Tillini, \& Ibrahim. (2013). Assessment of Mathematics Textbook for the Fourth Grade in Palestine according to TIMSS Requirements, Unpublished Master Thesis, Gaza: Palestine.

TIMSS2019, mathematics assessment frame work, Association for the evaluation of Educational Achievement (IEA). TIMSS\& PIRLS international study center, Lynch school of Education Poston college.

Lessani,A., Unus, A., Tarmiz, R., \& Mahud, R. (2014). Why singaporean $8^{\text {th }}$ grad students gain highest mathematics ranking in TIMSS(1999-2011). International education studies, 7(11), 173. https://doi.org/10.5539/ies.v7n11p173

Mullis, I.V.S, Martin, O, Ruddock, J, \& Sullivan, O, erberbere. (2008). TIMSS 2007, Assessment frame works, from IEA, TIMSS and Pirls, international study center, Iynch school of eduacation Poston college.

Mullis, I.V.S, Martin, M.O, Goh, 'S, \& Cotter, K.(Eds) (2016). TIMSS, 2015 , encyclopedia: education policy and curriculum in mathematics and science. Retrieved Poston College TIMSS and Pirls, international study center.Web site: http:// TIMSS and Pirls.bc.edu/TIMSS 2015/ensyclopedia.

\section{Copyrights}

Copyright for this article is retained by the author(s), with first publication rights granted to the journal.

This is an open-access article distributed under the terms and conditions of the Creative Commons Attribution license (http://creativecommons.org/licenses/by/4.0/). 